\title{
Inventarisasi Emisi Gas Rumah Kaca Pada Sektor Pertanian Dan Peternakan Di Kota Surabaya
}

\author{
Manggar C. Lintangrino, dan Rachmat Boedisantoso \\ Jurusan Teknik Lingkungan, Fakultas Teknik Sipil dan Perencanaan, Institut Teknologi Sepuluh Nopember (ITS) \\ J1. Arief Rahman Hakim, Surabaya 60111 Indonesia \\ e-mail: manggarcl@yahoo.co.id, Boedirb@gmail.com
}

\begin{abstract}
Abstrak - Penurunan beban emisi Gas Rumah Kaca (GRK) menjadi perhatian global seluruh dunia termasuk Indonesia. Seluruh kota di Indonesia wajib untuk membuat Rencana Aksi Nasional Penurunan Gas Rumah Kaca (RAN-GRK) dalam rencana pembangunan daerahnya sesuai dengan yang tercantum pada Peraturan Presiden No 61. Tahun 2011. Pemerintah menargetkan penurunan GRK sebesar 0,008 gigaton pada tahun 2020 untuk sektor pertanian. Sektor pertanian yang terdiri dari pertanian dan peternakan sendiri menghasilkan gas rumah kaca berupa $\mathrm{CO}_{2}, \mathrm{CH}_{4}$, dan $\mathrm{N}_{2} \mathrm{O}$. Kota Surabaya yang merupakan kota metropolitan memiliki potensi GRK yang cukup besar dari berbagai sektor termasuk sector pertanian dan peternakan, dibandingkan dengan kota metropolitan lain di Indonesia. Maka diperlukan inventarisasi emisi. Inventarisasi merupakan langkah awal untuk menentukan kebijakan selanjutnya dalam mengendalikan kualitas udara. Penelitian ini bertujuan untuk menentukan beban emisi GRK dan pemetaannya pada sebuah peta dasar Kota Surabaya menggunakan metode IPCC 2006. Beban emisi Kota Surabaya dari sektor peternakan sebesar $89,92 \mathrm{Gg}$ Ton CO2-Eq/tahun, dan sektor pertanian sebesar 6,1 Gg Ton CO2-Eq/tahun. Total beban emisi GRK Kota Surabaya adalah sebesar 93 Gg Ton CO2-Eq/tahun. Kecamatan Semampir menyumbang emisi paling besar pada sektor peternakan yaitu 63,5 Ton CO2Eq/tahun, dan pada sektor pertanian Kecamatan Pakal menyumbang emisi paling besar yaitu 1,4 Gg Ton CO2/tahun.
\end{abstract}

Kata Kunci- Faktor Emisi, Gas Rumah Kaca, Inventarisasi Emisi, Pertanian, Peternakan

\section{PENDAHULUAN}

$\mathrm{P}$ EMANASAN global merupakan isu global sehinga dibuatnya Kesepakatan Paris 2015 yang menggantikan Protokol Kyoto. Kesepakatan tersebut merupakan sebuah kesepakatan global antara negara maju dan negara berkembang untuk mengatasi masalah pemanasan global dan perubahan iklim. Dengan adanya kesepakatan tersebut, setiap negara baik negara maju, maupun berkembang harus berkontribusi dalam menurunkan emisi gas rumah kaca (GRK) mereka, termasuk Indonesia [1].

Indonesia yang merupakan negara yang turut menyumbang emisi dari berbagai sektor, salah satunya sektor pertanian yang didalamnya mencakup pertanian dan peternakan. Hal ini tercantum dalam Peraturan Presiden No 61 tahun 2011 Pasal 2, tentang Rencana Aksi Penurunan Emisi Gas Rumah Kaca yang disingkat RAN-GRK. Target penurunan GRK dari sektor pertanian sebesar 0,008 gigaton pada tahun 2020. GRK terdiri dari gas-gas karbon, terutama gas Karbondioksida $\left(\mathrm{CO}_{2}\right)$ dan Metana $\left(\mathrm{CH}_{4}\right)$. GRK merupakan gas alam sederhana, yang dihasilkan secara alami oleh mahkluk hidup, baik hewan, maupun tumbuhan [2].
Sektor pertanian melepaskan emisi GRK ke atmosfer dalam jumlah yang cukup signifikan, yaitu berupa $\mathrm{CO}_{2}, \mathrm{CH}_{4}$, dan $\mathrm{N}_{2} \mathrm{O}$ [3]. Menurut penelitian sektor pertanian menyumbang $10-12 \%$ dari total gas rumah kaca antropogenik , yang terdiri gas $\mathrm{N}_{2} \mathrm{O}$ dan $\mathrm{CH}_{4}$, Sedangkan, sektor peternakan menyumbang sekitar $18 \%-51 \%$ gas rumah kaca antropogenik, yang sebagian besar terdiri dari gas $\mathrm{CH}_{4}$ [4][5]. Emisi GRK diprediksi akan terus bertambah pada masa mendatang karena meningkatnya kebutuhan akan pangan yang disebabkan oleh penggunaan lahan marginal, dan peningkatan konsumsi daging [6].

Pemerintah mewajibkan setiap kota untuk menyusun rencana aksi daerah penyusunan emisi gas rumah kaca (RAD-GRK), tidak terkecuali Kota Surabaya. Inventarisasi emisi GRK sektor pertanian dan peternakan dilakukan di Kota Surabaya bertujuan untuk melengkapi data beban emisi yang ada di Surabaya. Kota surabaya sebagai kota metropolitan menjadi percontohan bagi skala kota besar lainnya untuk membuat kebijakan dalam hal inventarisasi emisi GRK. Kota Surabaya memiliki potensi GRK yang cukup besar karena memiliki populasi ternak sebesar 36.696 ekor ternak dan ditambah dengan populasi ternak yang datang dari luar kota untuk memenuhi kebutuhan daging di Surabaya, serta lahan pertanian sebesar $0,04 \%$ yaitu 1.461 Ha [7] jika dibandingkan dengan kota besar metropolitan lainnya dalam sektor pertanian dan peternakan, pada tahun 2014. Kota Jakarta sebesar 778 Ha yaitu 0,012 dari luas kota [8], sedangkan untuk populasi hewan ternak sebesar 39.995 ekor [9]. Untuk Kota Denpasar luas sawah sebesar 2.506 Ha yaitu $0,2 \%$ dari luas kota [10], sedangkan untuk populasi hewan ternak sebesar 183.897 ekor [11]. Sehingga jika dibandingkan Surabaya memiliki persentase pertanian dan peternakan yang cukup besar untuk menimbulkan gas rumah kaca.

Dalam mempermudah penetapan kebijakan mengenai pengendalian GRK, maka pembacaan hasil inventarisasi emisi perlu dipetakan. Pemetaan beban emisi GRK menggunakan Sistem Informasi Geospasial, yaitu pemetaan menggunakan peta dasar menurut wilayah dengan skala warna sehingga mempermudah pembacaan. Dengan adanya pemetaan beban GRK emisi hasil inventarisasi, maka dapat dilakukan pengendalian GRK yang efisien pada wilayah tersebut. Berdasarkan permasalahan yang telah dijelaskan sebelumnya, maka penelitian untuk mengetahui beban GRK dari sektor peternakan Kota Surabaya.

Adapun tujuan dari penelitian ini adalah untuk menentukan besar beban emisi GRK berdasarkan sumber 
pertanian dan peternakan di Kota Surabaya serta memetakan sebaran emisi GRK berdasarkan sumber pertanian dan peternakan di Kota Surabaya.

\section{GAS RUMAH KACA SEKTOR PERTANIAN DAN PETERNAKAN}

GRK yang perlu mendapat perhatian pada sektor pertanian adalah karbondioksida $\left(\mathrm{CO}_{2}\right)$, metana $\left(\mathrm{CH}_{4}\right)$, dan nitro oksida $\left(\mathrm{N}_{2} \mathrm{O}\right) . \mathrm{CO}_{2}$ sebagian besar dilepaskan dari proses pembusukan oleh mikroba, pembakaran serasah tanaman, dan dari bahan organik tanah [12]. Metana $\left(\mathrm{CH}_{4}\right)$ dihasilkan apabila dekomposisi bahan organik terjadi pada kondisi kekurangan oksigen, terutama pada proses fermentasi pencernaan ruminansia, kotoron ternak, dan lahan sawah [13] . $\mathrm{N}_{2} \mathrm{O}$ dihasilkan dari transformasi mikroba pada tanah dan kotoran ternak dan meningkat apabila ketersediaan nitrogen melebihi kebutuhan tanaman, terutama pada kondisi basah [14]. Tabel 1 menunjukkan periode konsentrasi dan nilai potensi pemanasan global untuk ketiga gas rumah kaca tersebut. Karbondioksida memiliki waktu tinggal di atmosfer paling lama di antara ketiga gas rumah kaca tersebut yaitu 5 hingga 2000 tahun. Meskipun demikian, $\mathrm{N}_{2} \mathrm{O}$ memiliki nilai potensi pemanasan global paling tinggi yaitu 298 kali potensi $\mathrm{CO}_{2}$. Jadi meskipun jumlah $\mathrm{N}_{2} \mathrm{O}$ yang teremisikan ke atmosfer lebih kecil daripada $\mathrm{CO}_{2}$, namun karena potensi pemanasan globalnya yang lebih besar maka akan menyebabkan efek pemanasan global yang lebih tinggi daripada $\mathrm{CO}_{2}$ atau $\mathrm{CH}_{4}$. [15](IPCC,2006)

$$
\text { Tabel } 1
$$

Nilai Potensi Pemanasan Global dan Waktu Tinggal Gas Rumah Kaca Dari Lahan Pertanian

\begin{tabular}{ccc}
\hline \hline Gas & $\begin{array}{c}\text { Waktu Tinggal di } \\
\text { Atmosfer } \\
\text { (tahun) }\end{array}$ & $\begin{array}{c}\text { Potensi Pemanasan } \\
\text { Global } \\
\left(\mathbf{C O}_{2} \text {-eq) }\right.\end{array}$ \\
\hline $\mathrm{CO}_{2}$ & $5-2000$ & 1 \\
$\mathrm{CH}_{4} *$ & 12 & 25 \\
$\mathrm{~N}_{2} \mathrm{O}^{* *}$ & 144 & 298 \\
\hline \hline
\end{tabular}

\section{METODE PENELITIAN}

Perhitungan beban emisi gas rumah kaca kota surabaya menggunakan metode perhitungan yang dikeluarkan oleh IPCC tahun 2006. IPCC (Intergovernmental Panel on Climate Change) adalah organisasi yang memberikan kebijakan berkaitan dengan perubahan iklim dengan tujuan memberikan sumber informasi objektif mengenai perubahan iklim [16] Rumus umum perhitungan beban emisi GRK adalah dengan mengalikan antara informasi aktivitas manusia dalam jangka waktu tertentu (data aktivitas, DA) dengan emisi/serapan per unit aktivitas (faktor emisi/serapan, FE) [17].

Data yang digunakan berupa data tahun 2015. Inventarisasi emisi gas rumah kaca dari sektor pertanian dan peternakan di Kota Surabaya dihasilkan dari 5 subsektor, yaitu subsektor fermentasi enterik, pengelolaan kotoran, pembudidayaan padi, pemupukan urea, dan pengelolaan lahan. Dengan batas ruang lingkup lahan pertanian yang dihitung hanyalah dari lahan budidaya padi, tidak termasuk pertamanan, dan perkebunan, dan gas rumah kaca karena pembakaran lahan pertanian.

Pengumpulan data aktivitas yang dalam penelitian ini menggunakan teknik survey primer berupa Kuesioner dan pengumpulan data langsung dari lapangan serta teknik survey sekunder berupa studi literatur dan data dari instansi terkait. Sumber data untuk data aktivitas dapat dilihat pada Tabel 2

Tabel 1

Sumber Data Masing-Masing Data Aktivitas

\begin{tabular}{|c|c|c|}
\hline Aktivitas Sumber Emisi & Jenis Data & Sumber Data \\
\hline \multirow[t]{2}{*}{ Enteric fermentation } & $\begin{array}{l}\text { Populasi ternak (jenis } \\
\text { dan Jumlah) }\end{array}$ & Dinas Pertanian \\
\hline & $\begin{array}{l}\text { Faktor emisi enterik } \\
\text { fermentasi }\end{array}$ & IPCC 2006 \\
\hline \multirow{4}{*}{$\begin{array}{l}\text { Pengolahan Limbah } \\
\text { Ternak (manure } \\
\text { management) }\end{array}$} & $\begin{array}{l}\text { Populasi ternak (jenis } \\
\text { dan Jumlah) }\end{array}$ & Dinas Pertanian \\
\hline & & \\
\hline & $\begin{array}{l}\text { Berat rata-rata } \\
\text { ternak }\end{array}$ & $\begin{array}{l}\text { Kuesioner dan } \\
\text { wawancara }\end{array}$ \\
\hline & $\begin{array}{l}\text { Faktor emisi } \\
\text { pengolahan pupuk } \\
\text { kandang }\end{array}$ & IPCC 2006 \\
\hline \multirow{5}{*}{ Pemupukan Urea } & Konsumsi Urea & AP3I /Kuesioner \\
\hline & Luas Area Tanam & Dinas Pertanian \\
\hline & Dosis Urea & Dinas Pertanian \\
\hline & Faktor Emisi Urea & IPCC 2006 \\
\hline & Luas Area Tanam & $\begin{array}{l}\text { Kementrian } \\
\text { pertanian/BPS }\end{array}$ \\
\hline \multirow{4}{*}{$\begin{array}{l}\text { Emisi Langsung dan } \\
\text { Tidak Langsung } \mathrm{N}_{2} \mathrm{O} \\
\text { dari Tanah }\end{array}$} & $\begin{array}{l}\text { Komposisi Pupuk N } \\
\text { (Urea,NPK,AS) }\end{array}$ & AP3I \\
\hline & $\begin{array}{l}\text { Dosis Pupuk } \\
\text { (Organik dan } \\
\text { Anorganik) }\end{array}$ & $\begin{array}{l}\text { Expert } \\
\text { Judgement/Kuesio } \\
\text { ner }\end{array}$ \\
\hline & $\begin{array}{l}\text { Kandungan } \mathrm{N} \text { pada } \\
\text { tiap jenis pupuk }\end{array}$ & Studi Pustaka \\
\hline & $\begin{array}{l}\text { Faktor emisi sawah } \\
\text { irigasi dan lahan } \\
\text { kering }\end{array}$ & IPCC 2006 \\
\hline \multirow{6}{*}{ Lahan Sawah } & $\begin{array}{l}\text { Luas sawah menurut } \\
\text { Jenisnya }\end{array}$ & $\begin{array}{l}\text { BPS/Dinas } \\
\text { Pertanian }\end{array}$ \\
\hline & luas areal panen & $\begin{array}{l}\text { BPS/Dinas } \\
\text { Pertanian }\end{array}$ \\
\hline & $\begin{array}{l}\text { Persen luas lahan } \\
\text { sawah berdasarkan } \\
\text { jenis tanah }\end{array}$ & $\begin{array}{l}\text { BB Litbang } \\
\text { Sumberdaya } \\
\text { pertanian }\end{array}$ \\
\hline & $\begin{array}{l}\text { Faktor koreksi jenis } \\
\text { tanah }\end{array}$ & Litbang Pertanian \\
\hline & Faktor skala rejim air & $\begin{array}{l}\text { Wawancara dan } \\
\text { Kuesioner }\end{array}$ \\
\hline & Faktor emisi padi & IPCC 2006 \\
\hline
\end{tabular}

Jumlah kuesioner untuk melengkapi data aktivitas pada sektor peternakan dihitung dengan rumus kjerce dan morgan, dan didapatkan jumlah kuesioner untuk sektor peternakan sebesar 76 sampel. Sektor pertanian menggunakan wawancara baik kepada kepada para ahli dari dinas pertanian, kepala gupuk tani, dan wawancara langsung 
kepada petani dilapangan yang dibagi menjadi blok-blok pada setiap kecamatan. Hal ini didasarkan pada satu luasan lahan sawah dapat digarap oleh banyak petani dengan sistem gotong royong, sehinga pembagian kuesioner didasarkan pada blok-blok sawah. Wawancara dan survey lapangan dilakukan pada blok sawah yang paling besar untuk dijadikan sampel pada setiap kecamatan dimana terdapat lahan sawah. Pembagian blok dapat dilihat pada Gambar 1.

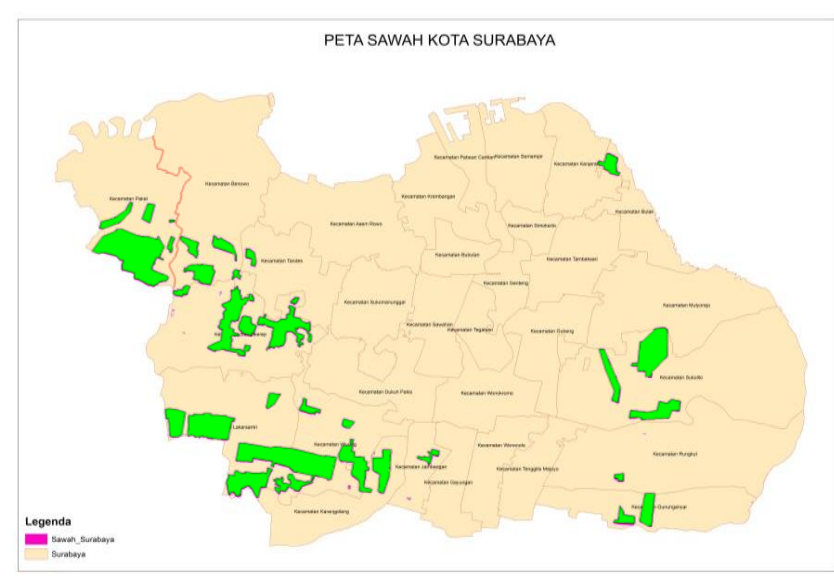

Gambar 2. Pembagian Blok Sawah Kota Surabaya

Data-data aktivitas yang telah didapatkan dianalisa sesuai metode IPCC 2006, untuk masing-masing Subsektornya.

\section{HASIL DAN PEMBAHASAN}

\section{A. Data Aktivitas dan Faktor Emisi}

Pada sektor peternakan data sekunder yang dibutuhkan adalah populasi ternak di Kota Surabaya, data tersebut didapatkan dari Dinas Peternakan Kota Surabaya. Untuk data berat rata-rata ternak dan sistem pengelolaan kotoran didapatkan dari hasil kuesioner. Dari hasil kuesioner tersebut didapatkan bahwa sistem pengelolaan dari ternak sapi 100\% dikelola dengan cara ditumpuk hingga kering/Dry Lot. Sistem pengelolaan Kotoran kambing 100\% dikelola dengan cara ditumpuk hingga kering/Dry Lot. Kotoran Unggas 37\% dikelola dengan cara penadahan, sedangkan $63 \%$ tanpa penadahan. Faktor emisi yang digunakan untuk sektor peternakan dapat dilihat pada pedoman IPCC Guidelines tahun 2006.

Perhitungan beban emisi sektor pertanian membutuhkan data sekunder luas area panen, produksi padi, jenis lahan sawah, jenis tanah pada lahan sawah, dan jumlah serta jenis pupuk yang diaplikasikan pada pembudidayaan padi. Data sekunder didapatkan dari Dinas Pertanian Kota Surabaya. Data primer yang mencakup lama budidaya padi, rezim air sebelum dan selama budidaya, dan varietas padi menggunaka sistem wawancara kepada para petani.

Dari hasil wawancara dan kuesioner bidang pertanian didapatkan bahwa untuk sawah irigasi rezim air selama budidaya adalah penggenangan secara terus menerus. Air irigasi diambil dari sungai besar di Surabaya, yaitu Sungai Jagir dan drainase setempat sehingga jarang terjadi kekeringan. Untuk sawah tadah hujan rezim air selama budidaya ini dipengaruhi topografi wilayah dan musim. Sebagian besar para petani di Surabaya hanya menanam padi pada awal musim penghujan dan pada akhir musim penghujan sehingga pada sawah tadah hujan sering terjadi penggenangan karena banjir. Rezim air pada lahan sawah di Surabaya biasanya digenangi air agar mudah ditanam sekitar satu minggu. Budidaya padi berlangsung selama 105-115 hari, dan rata-rata panen padi di surabaya adalah rata-rata 2 kali dalam 1 tahun jika tidak terjadi serangan hama atau banjir besar. Padi yang digunakan para petani di Surabaya adalah padi jenis Ciherang. Untuk faktor skala dan faktor emisi yang digunakan pada sektor pertanian Kota Surabaya dapat dilihat pada Tabel 3.

Tabel 3.

Nilai Faktor Emisi, Faktor Skala, dan Faktor Koreksi Sektor Pertanian

\begin{tabular}{|c|c|c|c|}
\hline Variabel & Faktor Emisi & Faktor Skala & $\begin{array}{c}\text { Faktor } \\
\text { Koreksi }\end{array}$ \\
\hline $\begin{array}{l}\mathrm{CH}_{4} \text { Lahan } \\
\text { Sawah }\end{array}$ & $16,1 \mathrm{~kg} \mathrm{CH}_{4} / \mathrm{Ha}$. hari* & & \\
\hline Varietas Padi & & & $\begin{array}{l}\text { Ciherang }= \\
0,57\end{array}$ \\
\hline Rezim Air & & $\begin{array}{l}\text { Irigasi terus } \\
\text { menerus }=1 \\
\text { Tadah Hujan } \\
\text { Banjir = 0,46 }\end{array}$ & \\
\hline $\begin{array}{l}\text { Rezim Air } \\
\text { sebelum } \\
\text { penanaman }\end{array}$ & & $\begin{array}{l}\text { kurang dari } 30 \\
\text { Hari = Tidak } \\
\text { diperhitungka } \\
\text { n }\end{array}$ & \\
\hline Jenis Tanah & & & $\begin{array}{l}\text { Entisol = } \\
1,02 \\
\text { Vertisol = } \\
1,06\end{array}$ \\
\hline $\begin{array}{l}\text { Emisi } \mathrm{N}_{2} \mathrm{O} \\
\text { Langsung } \\
\text { (Lahan Kering) }\end{array}$ & $\begin{array}{l}0,01 \mathrm{Kg} \mathrm{N} 2 \mathrm{O}-\mathrm{N} / \mathrm{Kg} \mathrm{N}- \\
\text { input }\end{array}$ & & \\
\hline $\begin{array}{l}\text { Emisi } \mathrm{N}_{2} \mathrm{O} \\
\text { Langsung } \\
\text { (Lahan Sawah) }\end{array}$ & $\begin{array}{l}0,003 \mathrm{Kg} \mathrm{N} 2 \mathrm{O}-\mathrm{N} / \mathrm{Kg} \mathrm{N}- \\
\text { input }\end{array}$ & & \\
\hline $\begin{array}{l}\text { Emisi } \mathrm{N}_{2} \mathrm{O} \text { tidak } \\
\text { langsung }\end{array}$ & $\begin{array}{l}\text { Volatilisasi }=0,01 \mathrm{Kg} \\
\text { N2O-N/(Kg NH3- } \\
\text { N+NOX-N } \\
\text { tervolatilisasi) } \\
\text { Pencucian }=0,0075 \mathrm{Kg} \\
\text { N2O-N/(Kg NH3- } \\
\text { N+NOX-N run off })\end{array}$ & & \\
\hline
\end{tabular}

\section{B. Perhitungan Beban Emisi GRK Kota Surabaya}

Beban emisi GRK pada sektor peternakan dan pertanian dihitung pada setiap kecamatan yang nantinya digunakan untuk pemetaan. Beban emisi dinyatakan dalam satuan jenis gas ( $\mathrm{Gg} \mathrm{CH}$, $\mathrm{Gg} \mathrm{N}_{2} \mathrm{O}, \mathrm{Gg} \mathrm{CO}_{2}$, per tahun) yang dikonversi ke dalam $\mathrm{CO}_{2}$ - Ekuivalen dengan menggunakan nilai global warming potential (GWP), yaitu 25 untuk $\mathrm{CH}_{4}$, dan 298 untuk $\mathrm{N}_{2} \mathrm{O}$ (IPCC 4th assasement).

Tabel 4.

Beban Emisi GRK di Kota Surabaya

\begin{tabular}{|c|c|c|c|}
\hline Kecamatan & $\begin{array}{c}\text { Total Emisi } \\
\text { GRK sektor } \\
\text { pertanian } \\
\text { Ton } \\
\text { CO2/tahun } \\
\text { sektor }\end{array}$ & $\begin{array}{c}\text { Total Emisi } \\
\text { GRK sektor } \\
\text { pertanian } \\
\text { Ton } \\
\text { CO2/tahun }\end{array}$ & $\begin{array}{c}\text { Total } \\
\text { Emisi } \\
\text { GRK total } \\
\text { Ton } \\
\text { CO2/tahun }\end{array}$ \\
\hline Tenggilis Mejoyo & 1486.80 & 0.00 & 1486.80 \\
\hline Wiyung & 143.52 & 597.90 & 741.43 \\
\hline Jambangan & 190.23 & 125.06 & 315.29 \\
\hline
\end{tabular}




\begin{tabular}{lrrr}
\hline \hline Sukolilo & 199.86 & 638.60 & 838.45 \\
Wonocolo & 664.06 & 49.25 & 713.31 \\
Semampir & 63581.37 & 0.00 & 63581.37 \\
Asemrowo & 1.86 & 0.00 & 1.86 \\
Bulak & 1117.51 & 522.10 & 1639.61 \\
Genteng & 0.00 & 0.00 & 0.00 \\
Karangpilang & 58.10 & 288.53 & 346.64 \\
Sukomanunggal & 0.71 & 0.00 & 0.71 \\
Rungkut & 120.49 & 69.84 & 190.33 \\
Dukuh Pakis & 202.00 & 0.00 & 202.00 \\
Pakal & 87.60 & 1302.64 & 1390.23 \\
Tandes & 135.97 & 179.21 & 315.19 \\
Sambikerep & 0.71 & 457.33 & 458.04 \\
Bubutan & 1281.51 & 0.00 & 1281.51 \\
Benowo & 6450.46 & 448.75 & 6899.21 \\
Gunung Anyar & 196.42 & 35.33 & 231.75 \\
Tambaksari & 537.95 & 0.00 & 537.95 \\
Wonokromo & 3472.95 & 0.00 & 3472.95 \\
Gubeng & 2715.13 & 0.00 & 2715.13 \\
Tegalsari & 751.29 & 0.00 & 751.29 \\
Gayungan & 0.00 & 34.24 & 34.24 \\
Krembangan & 779.64 & 0.00 & 779.64 \\
Lakarsantri & 116.30 & 1271.83 & 1388.13 \\
Kenjeran & 1587.09 & 14.90 & 1601.99 \\
Simokerto & 425.26 & 0.00 & 425.26 \\
Pabean Cantian & 382.73 & 0.00 & 382.73 \\
Mulyorejo & 197.15 & 38.74 & 235.89 \\
\hline \hline & & 0.00 & 37.58 \\
Sawahan & 66.922 & 6.07 & 93.00 \\
\hline
\end{tabular}

Beban emisi dari sektor peternakan baik dari peternakan Kota Surabaya, maupun dari tempat penampungan hewan pada rumah pemotongan dapat dilihat pada Tabel 4. Dari Tabel tersebut didapatkan bahwa pada sektor peternakan kota Surabaya menyumbang $86.922,28$ ton CO2eq pada tahun 2015, dapat terlihat bahwa kecamatan yang menyumbang emisi gas rumah kaca terbesar adalah kecamatan semampir yaitu sebesar 63.581,37 ton $\mathrm{CO} 2 /$ tahun, sedangkan kecamatan yang menyumbang beban emisi GRK yang paling kecil adalah kecamatan gayungan sebesar 0 ton $\mathrm{CO} 2 /$ tahun.

Beban emisi dari sektor peternakan baik dari peternakan Kota Surabaya, maupun dari tempat penampungan hewan pada rumah pemotongan dapat dilihat pada Tabel 5.8. Dari Tabel tersebut dapat terlihat dari sektor pertanian,Kota Surabaya menyumbang total emisi GRK sebesar 6074,25 ton $\mathrm{CO}_{2}$ eq pada tahun 2015. Kecamatan yang menyumbang emisi gas rumah kaca terbesar adalah Kecamatan Pakal yaitu sebesar 1302,53 ton $\mathrm{CO}_{2}$ /tahun, sedangkan kecamatan yang menyumbang beban emisi GRK yang paling kecil adalah Kecamatan Tenggilis Mejoyo, Semampir, Asemrowo,
Genteng, Sukomannggal, Dukuh Pakis, Tambaksari, Wonokromo, Gubeng, Krembangan, Simokerto, Pabean Cantian, dan Sawahan sebesar 0 ton $\mathrm{CO}_{2}$ /tahun.

Dari kedua sektor yang telah dibahas, total beban emisi terbesar di Kota Surabaya dihasilkan oleh kecamatan semampir, dan terbesar kedua dihasilkan pada kecamatan benowo.

\section{Pemetaan Penyebaran Beban Emisi GRK}

Pemetaan untuk keseluruhan wilayah surabaya dilakukan menggunakan software ArcGIS 10.2.1.Dalam ArcGIS telah disediakan peta dasar Kota Surabaya yang telah dibagi sesuai batas administrasi kecamatan. data beban emisi diinput ke dalam program dalam bentuk Tabel sesuai dengan masing-masing kecamatan. Pemetaan dibuat 6 range, pewarnaan untuk mempermudah pembacaan pemetaan dan perbedaan beban pada tiap kecamatan, maka dipilih 5 skala level pada program. Program ArcGIS akan secara otomatis membagi pewarnaan pada peta menjadi 6 range, sehingga pada peta dapat disimpulkan bahwa semakin gelap pewarnaan maka beban emisi yang dihasilkan semakin besar.

Berdasarkan hasil pemetaan, sektor peternakan pada Gambar 2, terlihat kecamatan semampir menyumbang beban emisi paling besar. Hal ini dikarenakan kecamatan semampir adalah pusat rumah potong hewan di Surabaya, sehingga hewan ternak yang memiliki faktor emisi besar terkonsentrasi di kecamatan tersebut. Sedangkan di daerah Surabaya Pusat,
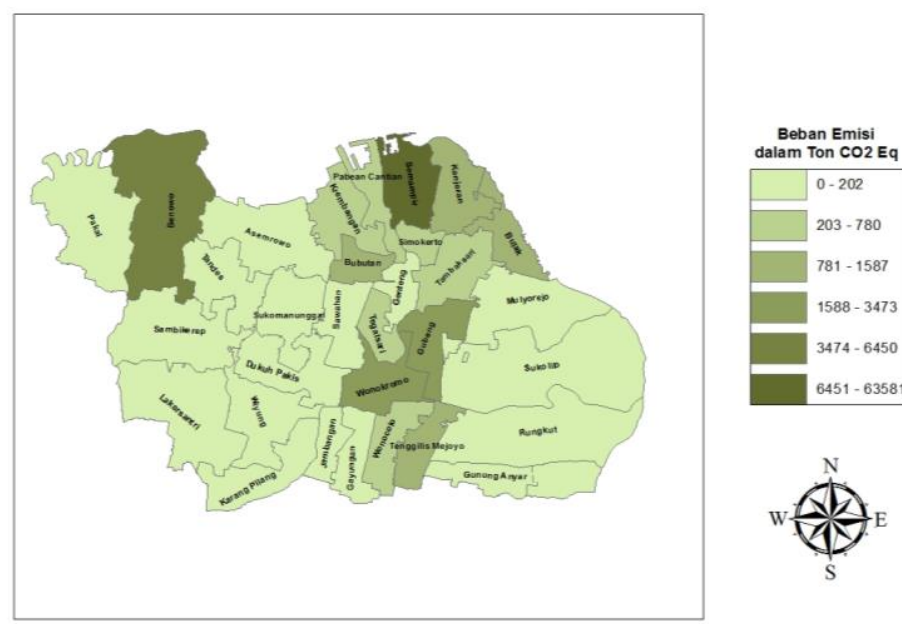

Gambar 2. Pemetaan Beban Emisi Pada Sektor Peternakan

beban emisi yang dihasilkan didominasi antara 0 hingga 202 ton $\mathrm{CO}_{2}$ Eq. Hal ini disebabkan karena tidak terdapatnya lahan untuk memelihara hewan ternak karena merupakan pusat kota berpenduduk padat,

Berdasarkan hasil pemetaan, sektor pertanian pada Gambar 3, terlihat kecamatan Pakal dan Lakarsantri merupakan penyumbang emisi GRK terbesar. hal ini dikarenakan dua kecamatan tersebut memiliki luas lahan untuk pertanian padi yang besar, dan memiliki luas panen yang paling besar, sehingga beban emisi yang dihasilkannya pun besar. Sedangkan didaerah Surabaya Pusat beban emisi yang dihasilkan didominasi antara 0 hingga 13 ton $\mathrm{CO}_{2} \mathrm{Eq}$ hal ini disebabkan karena pada daerah tersebut tidak terdapat lahan sawah. 
Keseluruhan beban emisi GRK ketika dijumlahkan antara beban emisi dari sektor Pertanian dan Peternakan yang terdapat pada Gambar 4, dapat diketahui bahwa penyumbang emisi GRK terbesar di Kota Surabaya berada pada Kecamatan Semampir dan Benowo.
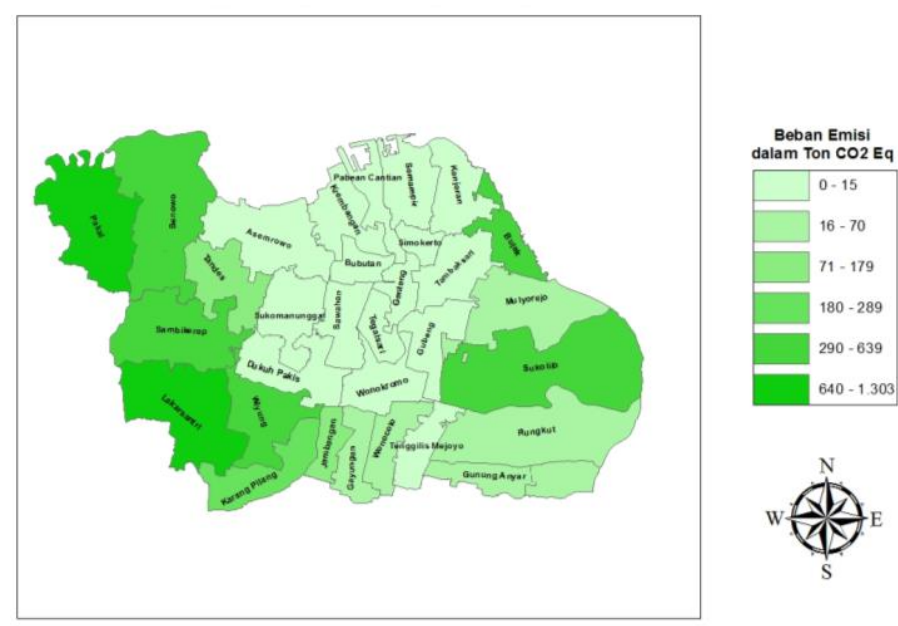

Gambar 3. Pemetaan Beban Emisi Pada Sektor Pertanian
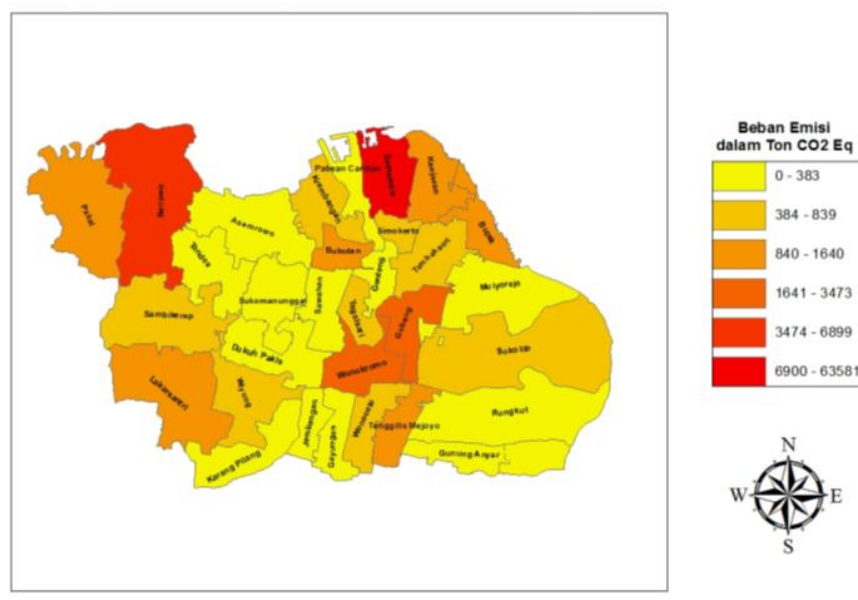

Gambar 4. Pemetaan Beban Emisi Total Kota Surabaya

\section{KESIMPULAN DAN SARAN}

Berdasarkan wilayah pertanian dengan luas lahan total budidaya padi sebesar 1.489 Ha dari seluruh kecamatan menghasilkan beban emisi GRK sebesar 5173,64 ton CO2eq, sedangkan dari sektor peternakan dengan ternak sapi potong, sapi perah, kambing, domba, kerbau, dan unggas dari seluruh kecamatan serta dari tempat penampungan hewan menyumbang beban emisi GRK sebesar 75.891 ton CO2eq.

Pemetaan beban emisi yang dilakukan pada sektor pertanian memperlihatkan bahwa kecamatan yang menyumbang emisi gas rumah kaca terbesar adalah Kecamatan Pakal yaitu sebesar 1110,53 ton $\mathrm{CO}_{2} /$ tahun. Pada sektor peternakan, kecamatan yang menyumbang emisi gas rumah kaca terbesar adalah Kecamatan Semampir yaitu sebesar 53.892,3 ton $\mathrm{CO}_{2}$ /tahun. pada perhitungan total beban antara sektor peternakan dan sektor pertanian, kecamatan yang menyumbang beban GRK paling tinggi adalah kecamatan semampir, yaitu sebesar 63581.37 ton $\mathrm{CO}_{2}$ /tahun, dan Kecamatan Benowo sebesar 6899.21 ton
$\mathrm{CO}_{2}$ /tahun Sehingga Pemerintah dapat berfokus untuk mereduksi emisi GRK pada Kecamatan Pakal dan Lakarsantri untuk sektor pertanian, Kecamatan semampir untuk sektor peternakan, serta Benowo karena gabungan beban GRK dari kedua sektor paling tinggi.

\section{DAFTAR PUSTAKA}

[1] Sukadri,D.2015. Kesepakatan Perubahan Iklim. Kompas (Jakarta) Sabtu, 3 Desember.

[2] Rusbiantoro,D.2008.Global Warming For Beginner. Yogyakarta: Penerbit O2 Penembahan Yogyakarta.

[3] Paustian, K., B.A. Babcock, J. Hatfield, R. Lal,B.A. McCarl, S. Maclaughin, A. Mosier, C.Rice, G.P. Robertson, and D. Zilbermen. 2004.Agricultural Mitigation of Greenhouse Gases:Science and Policy option. CAST Report R141 2004. 120 pp.

[4] Schils,R.L.M.,Olesen,J.E.,Prado,A.D.,2007. A Review Of Farm Level Modelling Approaches for Mitigating Greenhouse Gas Emissions from Ruminant Livestock Systems.Livest.Sci.12,240-251

[5] Goodland,R.,Anhang,J.,2009.Livestock and Climate Change: What if The Key Actors In Climate Change are Cows, Pigs, and Chickens?. World Watch Institute.pp 10-19.

[6] Surmaini, E., Runtunuwu,E.,Las,I. 2011.Upaya Sektor Pertanian Dalam Menghadapi Perubahan Iklim".Jurnal Litbang Pertanian, 30(1).

[7] Dinas Peternakan Provinsi Jawa Timur. 2014. Data Statistik Populasi ternak Kota Surabaya. http ://disnak.jatimprov. go.id /web/ layanan publik /datastatistik diakses tanggal 28 desember 2015.

[8] BPLHD Kota Jakarta.2014. Laporan Status Lingkungan Hidup Daerah Provinsi DKI Jakarta .Jakarta: Pemprov DKI Jakarta

[9] Kementrian Pertanian.2014. Data Populasi Ternak Menurut Provinsi.http://www.pertanian.go.id/ap_pages/mod/datanak. Diakses tanggal 28 Desember 2015

[10] Dinas Pertanian Kota Denpasar.2014. Perkembangan Luas Lahan Sawah dan Lahan Kering Kota Denpasar. http: //pertanian .denpasar kota.go.id /index.php/detail-download/4429/Perkembangan-LuasLahan -Sawah-dan-Lahan-Kering-Kota-Denpasar-Tahun-2014. diakses tanggal 28 desember 2015.

[11] Dinas Peternakan Kota Denpasar. .2014. Bank Data Dinas Peternakan , Perikanan dan Kelautan. http://bankdata.denpasarkota.go.id /index.php/arsipsubkategori/39/Dinas-Peternakankoma-Perikanan-\&-Kelautan-KotaDenpasar\#. diakses tanggal 28 desember 2015.

[12] Smith, P., Field, C.B. and Raupach, M.R., 2004. Engineered biological sinks on land. The global carbon cycle: integrating humans, climate and the natural world, pp.479-491.Mosier, A.R 2001. Exchange of gaseous nitrogen compound between agricultural system andthe atmosphere. Plant Soil 228: 17-27.

[13] Smith, K.A. and F. Conen. 2004. Impact of land management on fluxes of trace greenhouse gases. Soil Use Manag. (20): 255-263.

[14] IPCC (2006).2006. IPCC Guidelines for National Greenhouse Gas Inventories: Volume 2 -Energy, Prepared by the National Greenhouse Gas Inventories Programme, Eggleston H.S., Buendia L., Miwa K., Ngara T. and Tanabe K. (eds). Published: IGES, Japan.

[15] Risnandar, S.T. 2008. Mengenal IPCC (Intergovernmental Panel on Climate Change). http://kehutanan.risnandarweb.com/. diakses pada tanggal 16 Desember 2015.

[16] Kementrian Lingkungan Hidup.2012. Pedoman Inventarisasi Gas Rumah Kaca Nasional Buku II Volume 3: Metodologi Penghitungan Tingkat Penyebaran Emisi dan Penyerapan Gas Rumah Kaca, Pertanian, Kehutanan, dan Penggunaan Lahan Lainnya.Jakarta : Kementrian Lingkungan Hidup. 